\section{Gut microbes shape immunity}

Autoimmune disease in children could be caused by gut bacteria that inhibit immune development.

Surface lipopolysaccharide (LPS) is made by microbes such as Escherichia coli and helps immune cells to mature. Ramnik Xavier of Harvard Medical School in Boston, Massachusetts, and his team studied the gut microbiomes and clinical history of more than 200 children in various countries from birth until age 3 .

Finnish children, who had higher rates of autoimmune disease than those from Russia, also had higher levels of Bacteroides strains than of E. coli, whereas Russian children had more E. coli. In cultured human white blood cells, LPS produced by Bacteroides dorei inhibited the stimulation that is needed to promote immune-system development.

Certain immune-stimulating LPS types might be needed in early life to 'educate' the immune system to more accurately recognize foreign molecules.

Cell http://dx.doi.org/10.1016/

j.cell.2016.04.007 (2016)

\section{PLANETARY SCIENCE}

\section{Martian water} on the boil

Water boiling under Mars's thin atmosphere could explain some of the planet's puzzling geological features, such as gullies (pictured) and hillside streaks, which some scientists have attributed to liquid water flowing today.

A team led by Marion Massé

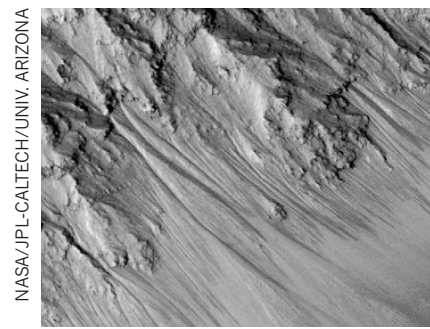

of the University of Nantes in France melted ice on top of a pile of sand in a laboratory chamber that simulated the Martian atmosphere. Water boiled as it seeped into the sand, causing grains to tumble downhill. Even with relatively small amounts of water, the flowing grains formed channels that were similar to those seen on Mars.

Earth-like quantities of liquid might not be required to form features on Mars, the authors say.

Nature Geosci. http://dx.doi. org/10.1038/ngeo2706 (2016)

\section{REPRODUCTIVE BIOLOG}

\section{Catching sperm for contraception}

Mouse and human sperm bind to specially designed polymer beads, which could one day be used to select sperm for fertility treatments or to block conception.

Mammalian sperm binds to the $\mathrm{ZP} 2$ protein, part of a matrix that surrounds the egg. Jurrien Dean at the National Institute of Diabetes and Digestive and Kidney Diseases in Bethesda, Maryland, and his colleagues attached an engineered portion of $\mathrm{ZP} 2$ to the beads, and found that they captured mouse sperm in lab dishes, preventing fertilization of most eggs in the dish. When beads were placed in mouse uteruses, animals gave birth to pups after about 70 days, whereas females with no beads did so after roughly 28 days.

The beads also selected for human sperm in a dish, and, once released, the sperm could bind to and penetrate eggs better than sperm that were not initially captured by the beads. Sci. Transl. Med. 8, 336ra60 (2016)

\section{ECOLOGY}

\section{Camera traps may aid conservation}

A study using motiontriggered cameras in the wild has revealed that grasslands and floodplains are home to the most diverse communities of mammals in northern Botswana.

Lindsey Rich of Virginia

Polytechnic Institute and State University in Blacksburg and her colleagues analysed more than 8,000 photographs of 44 species of mammal taken by 'camera traps' at more than 200 locations across the Okavango Delta of Botswana between February

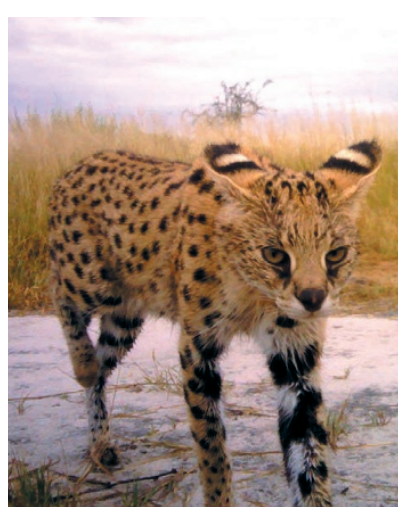

and July 2015 (pictured is a female serval; Leptailurus serval). They developed models to estimate the spatial distributions of the mammals, and found that species diversity increased with distance into protected areas. Larger species and herbivores benefited from these areas the most, whereas diversity of medium-sized animals was higher in non-protected areas.

The authors say that their methods could be an efficient way of gathering data for conservation of wildlife communities.

J. Appl. Ecol. http://doi.org/bfqr (2016)

\section{CANCER BIOLOGY}

\section{T cells team up with chemotherapy}

Immune cells called

T cells could make some chemotherapies more effective against ovarian cancer.

Rebecca Liu and Weiping

Zou of the University of Michigan in Ann Arbor and their colleagues studied human ovarian cancer cells in culture. They showed that fibroblasts - connective-tissue cells found in and around tumours — made tumour cells resistant to the platinum-based chemotherapy drug cisplatin by reducing DNA-damaging platinum levels in cancer cells. T cells in the tumour's environment, however, restored the drug's tumourkilling abilities by producing a protein called interferon- $\gamma$, which alters certain metabolic pathways in fibroblasts. In women with ovarian cancer, levels of a type of T cell called $\mathrm{CD}^{+}$were higher in tumours that were more sensitive to cisplatin.

The results suggest that a combination of platinumbased chemotherapies and drugs that boost T-cell responses could be promising against ovarian cancer. Cell http://dx.doi.org/10.1016/ j.cell.2016.04.009 (2016)

ENVIRONMENTAL SCIENCE

\section{UK food imports use scarce water}

Half of the United Kingdom's global water footprint is unsustainable.

Arjen Hoekstra and Mesfin Mekonnen of the University of Twente in the Netherlands quantified UK water consumption and found that the country uses roughly 5.5 billion cubic metres of surface and groundwater per year. About 5 billion $\mathrm{m}^{3}$ of that is accounted for abroad - mostly water used to produce imported food. Half of this comes from areas that use water unsustainably. For example, almonds are imported from central California, where rivers and groundwater are being depleted to grow this and other crops.

The authors recommend that Britain becomes more selfsufficient in food production and imports food from more water-abundant regions.

Environ. Res. Lett. 11, 055002 (2016)

\section{- NATURE.COM}

For the latest research published by Naturevisit:

www.nature.com/latestresearch 